\title{
Values Informing Professional Practice in Academic Professional Development
}

\author{
Roisin Donnelly \\ The Learning, Teaching and Technology Centre \\ Dublin Institute of Technology \\ Ireland
}

\begin{abstract}
While a significant body of work on the practice of academic development exists, research on academic developers (those charged with supporting the education of academic staff in higher education) as professionals is limited, and few have explored the profession from the perspective of academic developers themselves [22]. Specifically, this reflective report begins to address the question of how best to prepare and support current and future academic developers for their ambiguous and complex roles and their need to function within the changing environment of higher education institutions. Since embarking on a role in an Irish Higher Education Institution in 1999 as an Academic Developer, it has been crucial to consider my values as an educator, and how they inform the multifaceted role. A personal and professional value system certainly requires considerable thought as it is necessary to understand what it is that the academic developer wishes to evaluate in their work, why and for what purpose.
\end{abstract}

\section{Introduction}

The role of the professional body for academic developers internationally is more important than ever in providing much needed support an networking opportunities. This critically reflective report is structured under the Staff and Educational Development Association (SEDA) values and examples are given to illustrate each in action. SEDA is the professional body for academic developers in the UK and Ireland.

When one is new to teaching in higher education, advice and support from an academic developer (amongst others), can be invaluable. Equally, when one is a number of years down the teaching road, having an academic developer within the institution can be a way to reach out to try something different. Therefore a key aspect of the academic development role is to continue to motivate lecturers when it comes to continual development in teaching and learning; the 'journey' metaphor is overused today but it can be useful for the academic developer to bear in mind that immediacy of results for oneself and others is not always viable or even appropriate.

Within this role, it has been useful to continue to question the things that are either too familiar or too removed from my everyday concerns. My 'performance' as an academic developer comes from deeply within myself and therefore the constructs used are based on a mixture of personal beliefs, professional knowledge, practice and social context. Figure 1 shows these values and main influences on my work.

\section{Academic Development Values \& Influences

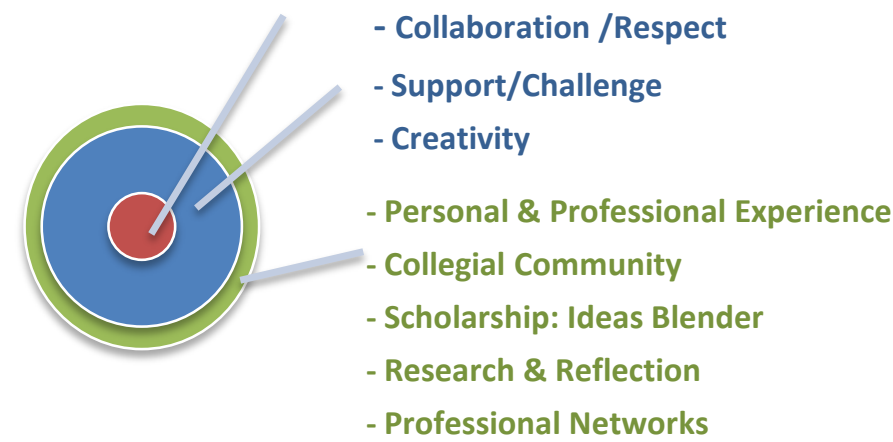

Figure 1. Range of values and influences on an academic development context

Academic development work is most often shared, occurring within what Frielick refer to as a dialogic where we are giving voice to or enabling the work of others [12]. Collaboration is an integral part of what we do - forming partnerships, combining ideas, building capacity for collaborative problem solving, working closely with colleagues across institutions and in professional networks, sharing responsibility and respecting autonomy. Personal knowledge is that store of experiential knowledge developed from my practice and reflection over duration of years in this role. I like the notion that as academic developers spanning many areas that we can be seen as idea blenders - we adopt ideas and concepts from outside of our domain and find ways to infuse those ideas into both our own work and that of the academics we support. When faced with a problem, it is not just about looking at what another teacher does or how another institution solved the problem. As idea blenders, we can use our expertise in higher education and blend it with outside expertise 
to create solutions that challenge the status quo. In terms of the challenges for the academic development role, pedagogy is not becoming any easier; in fact, many academics argue that the corporatization of higher education has had negative implications for their ability to be effective teachers. A recent Guardian blog post highlighted this very issue - and their Academics Anonymous [4/2/14] series to allow academics to vent their opinions on this emotive topic is an interesting approach. Similarly within the U.S. higher education environment, Chomsky has spoken and written at length on the considerable influence of corporation on higher education [8].

Within this charged working context, a key aspect to the academic developer's educational values is creativity - how can one be creative in the role, and how can one support others to be so. Jackson conducted a note-worthy study with 18 academic developers to help promote a professional conversation about how they view the role of creativity in their role [14]. I use it in my relationship and work with the academics that I support - how I relate, understand, empathise with, engage, enthuse, change perceptions and co-create meaning. I concur with Jackson's suggestion that enabling other people to be creative is part of the creative work of the academic developer.

\subsection{Contextual Influences on Academic Development}

Fraser advises that we should be wary not to neglect the interplay of beliefs, knowledge and practice within the institutional and personal contexts in which we practice [11]. The scope of our work is intricately embedded within our individual contexts, but other academic developers may find congruency in these contexts. Working across four colleges in my role, I am privileged to have what Angelo calls a 'bird's eye' view of activity within my overall institution [1]. Within Irish higher education, a National Forum for the Enhancement of Teaching and Learning in Higher Education has been established for the first time. In their commissioned 2013 report, they pose a set of questions for leaders in our institutions to consider, and some that are relevant for academic developers to consider are:

- What steps do I take to ensure that an individual teacher feels empowered and supported in developing their teaching skills?

- How do we support teaching staff in their efforts for diversifying student needs? (flexible learning paths and speeds, blended delivery)

It is important as developers to engage with this these types of educational fora to work with others across the sector to focus our communal energy and expertise on the challenges of collective importance. Having a clear knowledge of national and international frameworks for facilitating academic professional development will be useful for these discussions.

\section{Understanding how Academics Learn}

Perry suggests that ideally academic development should be situated within existing academic cultures and focus on conceptual change [19]. Having an emphasis on academic reflective practice on a 'Learning Theories' module as part of an accredited professional development masters programme is an integral part for the academics' thinking on the module. It cleans it up, brings into focus the key issues on theories, raises new questions, and stimulates more thinking. Through their reflective postings online, the academics are friendly, engaging, and reflexive. It is a forum for reaching out to each other and asking questions that they perhaps did not know the answer to. They can make recommendations - say that they think something is good and suggest that others try it, read it, or think more about it.

This module is the foundation for academic on the programme for an understanding of how people learn, and knowing that is central to all that they do as educators. Through facilitated discussion, they are led to consider why they do things in a particular way - what theories inform their work, and evaluate whether the activity-driven approach that they take to exploring learning theories in different contexts and practices is working well. In this context, I am always drawn back to the Palmer concepts of identity and integrity, and learning community, and these underpin my work [18].

\section{Developing People and Processes}

Some developers are uncomfortable with the notion that academic development implies a movement from an undesirable position to a desirable one, and perhaps arguing that this implies superior knowledge on the part of the developer; this certainly has resonance for my practice. This notion of transfer from 'us to them' has proved an unsettling one for colleagues over the years. It is one aspect of our role that each of us have to find our own way to deal with.

Embracing Media More and More Media is a mantra that exists in academic development today. Sparks brings some key perspectives forward about what influences professional learning; among them being the need to expand our repertoire of researchbased instructional skills, our development should be embedded in and connected to our daily work, and we should be surrounded by a culture that encourages innovation, experimentation, and continuous improvement [23]. This encapsulates a goal of trying out new media (daily) on an ongoing 
basis to support my own skills development, and so I am better informed when discussing technology with academics across the institution.

I have increasingly found social media tools useful for my own learning, and while it is almost impossible to read everything that I have signed up for, I have also become more adept at skimming for relevance, trusting certain names and authorities, and accepting that I cannot and should not try to read everything. I realize that even if I use only a little of what I see, I am still much better informed, and thinking more creatively about learning and learning technology, as a result of my exposure to such information. It has also increased my confidence in sharing what I believe to be useful information with academics across the disciplines, and this is something I now do much more frequently in my work. Johnson raises as an issue in higher education a continued lack of digital literacy skills development for teachers as a key challenge for this sector [15]. As academic developers and practitioners, we need to continually evolve such skills ourselves, and facilitate their development in the educators we educate.

It is not just a case of having to embrace technology, though. It is a case of recognizing that it offers an unrivalled opportunity to leverage its prevalence and influence in the lives of the academics we support, to help them create powerful teaching and learning opportunities, based on sound pedagogical approaches. As Palmer concludes, 'Perhaps if I go where my students are, they will move closer to where I would like them to be' [18]. It is important to be willing to try out new tools - whether using an app or tool once, or becoming a dedicated user, simply trying it out may give me an idea for something else, or helping one to think more creatively. In the collegial climate that exists in academic development, sharing new-found knowledge with the academics can be one of the more enjoyable aspects of our daily work.

\section{Scholarship, Professionalism and Ethical Practice}

As an academic developer, my personal integrity derives from ability to respond to situations in ways that are consistent with my identity. I believe this can guide my own professional goals and practices, but can also contribute to the meaningful and sustained development of individual academics and my institution. It is essential to know myself, my discipline, and my community. I believe it is how I apply these attributes in practice that most strongly defines my identity: empathy, commitment, honesty, respect (the expertise of others), openmindedness, openness to change, ability to relate to the experiences of others, communication skills, and collegiality.

Nixon suggests that we need our expertise to make connections among self, learners, the knowledge to be learned, and the context - this is useful for applying the concepts, practical tools, and process skills embedded in our expertise to help others in turn achieve their teaching goals [17]. Considering the impact of my work on others is especially evident when assessing the work of my peers on our accredited masters Programmes. Academics are committed to scholarship with high standards, and this is an integral message of the 'Academic Writing and Publishing' module that we offer to academics. Supporting the mixed discipline participants so that their academic writing builds on and cites other relevant content, is thoughtful and logically coherent, uses the forms of inquiry and specialized language accepted by their disciplines, and the stance taken toward the subject is objective, rational, and reasoned - but we have consistently found that one of the missing ingredients is their lack of awareness on how to connect with their readers/audience through their writing. I enjoy working with the academics to instil much greater confidence in joining the research conversation on their chosen topic, and use examples drawn from my own publications experience to illustrate this.

Through this module and a new pedagogical research journal that was co-founded within our academic development centre, entitled the Irish Journal of Academic Practice (IJAP), we aim to reach out to academics across our institution to support making teaching and learning more scholarly and intellectually rich; but one of the most interesting discussions centres around whether journal articles and books are the only acceptable forms of scholarship? There have been recent conversations about the best way to shape and form new ways of communicating so that they meet our needs for information, ideas, and inspiration and still uphold the high standards we all endorse.

The intention with the journal is to grow the network of staff involved in research in learning and teaching across the institution. Through the use of a wikispaces site to facilitate collaboration amongst IJAP authors, it is hoped that we can build capacity of activity in pedagogical research around our postgraduate programmes and further across the institution. It is axiomatic that academic staff should have an up-to-date knowledge of their subject and discipline, and many of our staff teach in areas that relate directly to a profession, public or industry sector. Therefore, the insights gained from their research, contributions to professional practice and consultancy activity can feed back into their teaching, and that of colleagues through dissemination in IJAP. 
Pulling togther a selection of informed peer reviewers was also key for the integrity of the journal. We aimed to include reviewers who are doing research in related areas to those covered by the scope of the journal. As is well established, reviewers play an essential part in research and in scholarly publishing, and we were keen on introducing an effective peer-review processes to uphold the quality and validity of individual articles and the overall integrity of IJAP. However, it is also known that it is difficult to not only find and keep reviewers, but encourage them to meet deadlines. To this end, to improve and streamline the peer-review process for the journal, a collaborative wiki was set up to support the peer review process. This collaborative process can challenge the assumption that peer review can only be handled by journal editors. By embracing a new culture of open, transparent and independent research evaluation, it is hoped that the academic community in the journal can more productively contribute to pedagogic knowledge. This open peer review is of course not new, but for our institution it is an opportunity for such a collaborative process to especially support new teachers and researchers entering their fields who have a genuine aspiration to contribute to pedagogic knowledge, yet are unsure how to begin.

From an ethical perspective, collegiality is reflected in the relationships that emerge within departments in the institution. It is often evidenced in the manner in which academics interact with and show respect to one another, work collaboratively in order to achieve a common purpose, and assume equitable responsibilities for the good of the discipline as a whole. It is not an exaggeration to say that in higher education, collegiality is the cornerstone of professional work. In working with colleagues on learning and teaching projects across the disciplines, it is useful to establish ground rules for how we interact, and one that I always like to include is 'we agree to disagree without being disagreeable!' This acknowledges that dissonance in collaborative projects can exist but reflects the concept that every person pledges to treat colleagues with dignity, respect, and civility and to do their fair share of the workload. In an environment of uncertainty and unpredictability, it is useful for me to recognize that the most valuable assets in an institution are its people and the intellectual capital they possess and the culture they create.

In supporting professionalism within myself and support it in others, I will continue to develop approaches which acknowledge the dynamic nature of our practice, the complexity of what Whitchurch has called the 'third space' in which we work, and seek to carve a commitment to my own continuing professional development [27]. As Barnett affirms "the professional is a living project in creation" [2].

\section{Working in and Developing Learning Communities}

The academic profession is often portrayed as composed of persons strongly driven by intrinsic motives who concentrate primarily on the substance of teaching and research...academics seem to be more prone than the majority of professions to pay attention to the rites and symbols associated with their work (memberships/titles in selective academies)...it is viewed as a highly attractive profession in terms of challenging tasks and leeway to shape one's work [26]. It is always useful for academic developers to join relevant learning communities. In all such networks, we can give each other feedback and encouragement and appropriate practical and academic help, sharing ideas, and practice about how best to support learning and teaching and professional development. These professional associations allow all involved to share reflections and theory about how we support learning and development in our institutions. Arguably it also lets us become more of a 'change agent' as we are surrounded by a supportive group of people that can and will give honest feedback. Being a change agent in education is probably one of the most difficult, thankless and frustrating jobs; it certainly can be easier to be a complacent educator. Being innovative takes a kind of persistence and passion for our work that is inextinguishable. In network discussions, no one feels defensive in the exchange of feedback, because the members of the networks have been intentional in creating a trusting environment where constructive comments are welcome, especially thought-provoking constructive criticism on dealing with change in our contexts.

Increasingly, we are being called upon to facilitate learning in community with respect to the strategic goals of the institution and become more involved in the political systems therein. This shift has made the 'learning in community' role more complex, in that developers can often function as the "boundary spanners" discussed [28]. Debowski suggests that we educate, influence and enable institutional change through our daily work [9]. The underlying driver for our work is change, and it is an integral part of our work as developers to continually explore this.

\section{Working Effectively with Diversity and Promoting Inclusivity}

The current context in which academics are working is one of change. So many areas of higher education have changed during recent decades, including major changes to the role of academics, together with the introduction of new approaches to the curriculum and assessment. In addition, 
importantly there is growing awareness and dialogue about how difficulties in student learning are conceptualised and involve additional support for learning. These changes have involved the development of new understandings about the needs of students with learning difficulties. Such developments have affected the professional identity as well as the roles and responsibilities of many academics. It also has implications for how academics are trained and supported in their professional development.

As academic developers, we have a clear sense that both we, and the staff we support, are all unique. We aim to remember this and take it into consideration when working with others so that we can interpret our differences as enrichment opportunities and be accepted, respectful and inclusive. Our development approaches need to be flexible and our ideas and toolkits versatile, adaptable and invigorating. We need to practise what we preach by living and modelling the approaches we wish academics to adopt; thereby we need to exemplify congruence between our actions and our recommendations to others.

In order to work effectively with diversity and promote inclusivity, academic developers need to adjust practices to a specific situation, a specific group, a specific individual. As Neame argues interventionalist approaches work better at initial stages and should be seen as a temporary solution and a way in towards adapting democratic development and the creation of learning communities, collaborations and partnerships to grow and develop together [16].

Like all similar academic development centres, an important part of our work is supporting academics in projects that encourage diversity of experience and widening participation; we hold seminars, invite guest speakers and work with academics across the disciplines in researching their practice and working with suitable external organisations. This work feeds into an Irish crossinstitutional Activity Database for supporting nontraditional groups in higher education which contains short case-studies describing what teaching staff do/have done to enhance the learning experience for all their students.

\section{Continuing Reflection on Academic Professional Practice}

A key aspect of our role is to support rigour and reflection in other academics. We are consistently working with staff to raise awareness that reflection can become a very conscious and deliberate activity, and has significance in shaping their learning. Within our postgraduate programmes, reflective practice is an iterative process rather than a one-off event, involving repeated cycles of examining practice, adjusting practice and reflecting upon it, before trying it again.

In the Postgraduate Diploma in Third Level Learning and Teaching, reflective processes involve creating meaning around teaching practice, which is inherently collaborative, and the resulting understanding can provide a starting point for adapting practice. Although some academics might often reflect on their teaching in a spontaneous and natural way, reflection can be facilitated using more directed reflective processes such as via microteaching sessions and peer and tutor observations. These activities recognise the importance of the collegial nature of academic work.

Through the use of portfolios and ePortfolios on our postgraduate programmes, we try to move the academics in their thinking from following a requirement to reflect to extend into their professional practice more of a need to reflect. This is all to help the development of personal qualities such as increased self-confidence, as well as the establishment of supportive relationships between those involved in the reflective processes, and ultimately transformation of practice for all involved. We have found that reflective practice can also enhance academics' ability to mentor and develop others, especially when there are early career academics working alongside their more experienced colleagues.

Failure is an imperative part of the creative process, and it is important that we encourage our academic participants to be brave enough to try new ideas in and outside of the classroom. They will spend plenty of time standing up to critics and pushing through the red tape just to try out their ideas, and we hear this all the time from the apprentice lecturers working in the vocational sector in our institution.

\section{Challenges Facing Academic Developers}

There are certainly challenges for developers in supporting leadership and dealing with institutional change. By being on relevant committees, we can work with colleagues in supporting academics for the preparedness for change, which is a vital element in any change journey. Research suggests that a high proportion of change efforts fail, attributable in part to failure to establish sufficient readiness for change [3].

Successful implementation of any change initiative depends on more than just good action planning - it also depends on engaging and empowering stakeholders in taking change forward; having a role on relevant institutional committees can introduce the academic developer to the key stakeholders. Any change initiative is likely to encounter resistance in some form. It is 
important to anticipate and understand likely sources of resistance, develop techniques for countering resistance, and use resistance positively as an opportunity for dialogue and development. The success of a change initiative can be judged on the extent to which change is embedded, consolidated and sustained - in other words, the extent to which it is 'owned' by others in order to have a lasting, positive impact on my institution.

Certainly then two main challenges for academic developers are dealing with change in faculty development/HE and understanding the nature of academic leadership. It can be useful to gain insights into how different institutions have addressed some change-related issues, as well as networked with other professionals who share an interest in change. Ultimately it is about being in a strong position to adapt and apply knowledge, tools or approaches to one's own context. Given the seismic institutional changes that can take place, it is important for the academic developer to develop skills and capabilities in leading future relevant specific change initiatives in their institution.

Dimensions of leadership are evidenced in every aspect of the academic development role. Increasingly, academic developers are called upon to provide leadership in problem solving and change at the institutional level [10]. Blackmore suggest that leadership expertise is tacit, closely related to a situation and learnt often by observing others [4]. What I would like to bring forward into my own practice for helping bring about effective change in my institution is by looking at more ways of getting feedback on my performance, keep participating in many different forms of professional development, analysing what I do in a structured way, by building networks, try to understand the decision-making process of others (through observation), consider all the stakeholders in the change process and ultimately to think about the evidence needed to support the changes I want to make in my current and future practice [7].

By exercising identity and integrity in my role, I can demonstrate credibility, fairness, honesty, connection, enthusiasm, genuineness, commitment, competency, and openness characteristic of effective leaders [20] [21]. A study by Taylor, although set in an Australian context, has resonance as she argues that a synergy exists among variable characteristics of the person, the academic development role, development strategies, and institutional context, and this can determine successful practice and leadership in any given institution [25].

The discussion on the opportunities and consequences of the changes that we meet in our role provides useful insights and this work is useful for prompting the academic developer to reflect on what else they might do, and what direction they might move in for the future [13] [24]. It takes time to change practice and to make lasting change, so new learning must become a part of the academic developer's routine. Engaging in rich debates with fellow developers about issues affecting academia today, may prompt one to question practice. Crossing subject boundaries to good effect can help form or strengthen valuable and valued working relationships with academics upon whose thinking and experience one can draw.

Based on the review of educational values discussed above, Table 1 consists of questions that academic developers can continue to explore for allowing these values impact on their role and practice.

\section{Understanding how academics learn}

- How do we integrate and facilitate adult learning principles with academics (who are also our peers)? - allow for hands-on, experiential learning, value all experience, provide 'takeaways' that can be used in practice right away

Scholarship, Professionalism, Ethical Practice

- What do we experience when working with academics?

- We have unique and privileged access to academic work across the institution and need to find a way to deal with being seen by others as institutional models or even the conscience for good teaching

Working in, and developing learning communities

- What is the most suitable environment to cultivate when supporting communities of academics? - ensure the environment (department \& institution) allows for mistakes to happen; sometimes when we are trying to improve or try something new out, things may not go perfectly; this is all part of being innovative and improving our collaborative skills

\section{Working with diversity and promoting inclusivity}

- How can we involve academics in the planning and development process of these important events? - keep asking them what they want/need or are interested in currently

\section{Continuing reflection on professional practice}

- How do we reflect on our work as academic developers?

- Professional development portfolios are a useful vehicle for reflection

\section{Developing people and processes}

- How can we continue to support the development of individuals and academic-led initiatives? provide diverse opportunities that take into account the lack of time academics may have: have 24 hour opportunities (short videos, a resource website, a place where academics can talk, collaborative resources etc 


\section{Conclusion}

For anyone in a leadership role, it is important to reinvent oneself professionally, and as academic developers leading learning and teaching in our institutions, we need to continue to think clearly about the role of professional development and for me, it is helpful to position myself as 'learner first' and figure out what new skills I must gain to be able to lead other educators through changes within my institution.

The academic development role is certainly challenging and definitely requires collegial support. Engaging with professional networks and communities can provide opportunities to reflect and receive feedback and support from like-minded colleagues. We must be provided with the time and resources to accomplish meaningful change. Boon has described academic development not an intentional career choice but as a 'destination that seeks us' [5]. Like Breslow, I feel that I am fortunate to have a role that enables me to "live my values" which allows me to extend and deepen my knowledge, work creatively within my institution and other organisations and ultimately empower and prepare others with what has called a disposition for lifelong learning [6] [17].

\section{References}

[1] Angelo, T. (1999). Doing academic staff development as though we valued learning most: transformative guidelines from research and practice. HERDSA Annual International Conference. Online, Accessed 2 February 2014 from

http://www.herdsa.org.au/branches/vic/Cornerstones/auth orframeset.html

[2] Barnett, R. (2008). Critical Professionalism in an Age of Super Complexity. In B. Cunningham (Ed.), Exploring Professionalism (pp.190-208). London: Bedford Way Papers.

[3] Beer, M., \& Nohria, N. (2000). Cracking the Code of Change. Harvard Business Review, 78(3), 133-141.

[4] Blackmore, P., \& Blackwell, R. (2006). Strategic leadership in academic development. Studies in Higher Education, 31(3), 373-387.

[5] Boon, S., Matthew, B., \& Sheward, L. (Eds.). (2010). Creating a Profession - Building Careers in Educational Development. Staff and Educational Development Association Special 27.

[6] Breslow, L. (2010). An educational developer's autobiography. (S. Boon, B. Matthew, \& L. Sheward, Eds.) Creating a Profession - Building careers in educational development. Staff and Educational Development Association Special 27, pp. 33-35.
[7] Brungardt, C.L. (1998). The New Face of Leadership: Implications for Higher Education. Online, Accessed 14 December 2013 from

http://www.nwlink.com/ donclark/leader/lead_edu.html\# sthash.INVnwskx.dpuf

[8] Chomsky, N. (2011). Academic Freedom and the Corporatization of Universities. Speech at the University of Toronto, Scarborough, April 6, 2011.

[9] Debowski, S. (2012). The New Academic: A Strategic Handbook. London: McGraw-Hill Education.

[10] Diamond, R. M. (2005). The institutional change agency: The expanding role of academic support centers. In S. Chadwick-Blossey \& D. R. Robertson (Eds.), To improve the academy (Vol. 23, pp. 24-37). Bolton, MA: Anker Publishing.

[11] Fraser, K. (2001). Australasian Academic Developers' Conceptions of the Profession. The International Journal of Academic Development, 6(1), 54-64.

[12] Frielick, S., \& McLachlan-Smith, C. (1999). The value (added?) of academic development. HERDSA Annual International Conference.

[13] Gibbs, G. (1988). Learning by Doing: A Guide to Teaching and Learning Methods. Online, Accessed 1 November 2013 from http://www2.glos.ac.uk/gdn/gibbs/ch4_3.htm

[14] Jackson, N. (2013). Educational Developers' Perspectives on Creativity in Educational Development. Keynote presentation at SEDA's 2013 conference on Creativity in Educational Development. Online, Accessed 2 February 2014 from http://www.normanjackson.co.uk/uploads/1/0/8/4/10842 717/developer_perspectives_on_creativity.pdf

[15] Johnson, L., Adams, S., \& Cummins, M. (2012). The NMC Horizon Report: 2012 Higher Education Edition. Austin, Texas: The New Media Consortium.

[16] Neame, C. (2011). Exploring Models of Development of Professional Practice in Learning and Teaching in Higher Education: What Can We Learn from Biology and Marketing? Educate, 11(1), 9-19.

[17] Nixon, J. (2008). Towards the Virtuous University: The Moral Bases of Academic Practice. New York: Routledge.

[18] Palmer, P. (1998). The courage to teach. San Francisco: Jossey-Bass.

[19] Perry, D.M. (2013). Go Where the Students are. The Chronicle of Higher Education. Online, Accessed 7 December 2013 from http://chronicle.com/article/GoWhere-the-Students-Are-/138801/

[20] Ramsden, P. (1998). Learning to lead in higher education. London: Routledge. 
[21] Senge, P. M. (1999). The dance of change: The challenges of sustaining momentum in learning organizations. New York: Currency/Doubleday.

[22] Shaffer, C.E. (2011). In their own voices: Faculty developers' perceptions of their professional identity and knowledge acquisition strategies. Unpublished thesis, Proquest.

[23] Sparks, D. (2013). The 6 Fundamental Ingredients of Robust Professional Development. Online, Accessed 14 January 2014 from http://dennissparks.wordpress.com/2013/11/26/the-6fundamental-ingredients-of-robust-professionaldevelopment/

[24] Stefani, L. (2003). What is staff and educational development? In P. Kahn \& D. Baume (Eds.) A Guide to Staff and Educational Development (pp.9-23). London: Routledge.

[25] Taylor, K.L. (2005). Academic Development as Institutional Leadership: An interplay of person, role, strategy, and institution. International Journal for Academic Development, 10(1), 31-46.

[26] Teichler, U., Arimoto, A., \& Cummings, W.K. (2013). The Changing Academic Profession. London: Springer.

[27] Whitchurch, C. (2008). Shifting boundaries; the emergence of third space professionals in UK higher education. Higher Education Quarterly, 62(4), 377-396.

[28] Williams, P. (2010). Special Agents: The Nature and Role of Boundary Spanners. Paper to the ESRC Research Seminar Series - 'Collaborative Futures: New Insights from Intra and Inter-Sectoral Collaborations', University of Birmingham, February 2010. 